\title{
Integration Between ERP Software and Business Intelligence in Odoo ERP: Case Study A Distribution Company
}

\section{Yulia Kendengis and Leo Willyanto Santoso}

Correspondence Author: Yulia Kendengis, Informatics Department, Petra Christian University, Indonesia

Received date: 12 January 2018, Accepted date: 10 March 2018, Online date: 2 April 2018

Copyright: (c) 2018 Yulia Kendengis and Leo Willyanto Santoso. This is an open-access article distributed under the terms of the Creative Commons Attribution License, which permits unrestricted use, distribution, and reproduction in any medium, provided the original author and source are credited.

\begin{abstract}
Odoo is an open-source ERP software. Odoo has advantage in price because it's free. And from the functional side, Odoo has been equipped with more than 4500 modules, one of them is business intelligence (BI). BI is a solution and technique that helps company to understand about the business situation to make effective business decisions and meet their objectives. A study about the integration between Enterprise Resource Planning and BI in Odoo ERP will be explained in this paper. In the case study, we used sales data from a distribution company.
\end{abstract}

Key words: Business Intelligence, ERP, Odoo

\section{INTRODUCTION}

BI transforms raw data into meaningful metrics reflective upon historical, current and predictive business operations and performance. In the past, the activities of BI were performed through gathering data from multiple sources manually, manipulating data in spreadsheets, with a static report output. The data should be gathered from some functional areas. These activities are takes so many times. But today, ERP solutions come with integrated BI modules that enable company to provide dynamic report. It provides the users with something what they want to see and whenever they want to see it. The benefit is its ability to give company a real-time look at the data they need to make intelligent decisions in the short and long terms. For example, a sales manager wants to get data about sales analysis, which products are harming the company. With a quick glance at the dashboard, the sales manager will be able to see the information about the sales analysis. He or she can analyze the factors that cause the products loss. One of the ERP software available today is Odoo. Odoo is an open-source ERP Software integrated with BI module. It provides robust analytical capabilities, such as access to reports and dashboard management. It also has advanced analytical features that allow us to view data from different sources.

\section{Literature:}

2.1 Business Intelligence:

Business Intelligence (BI) is a term consisting of technologies and processes for gathering, storing and analysing data to improve decision making [1-3].

Some researches about BI implementation in industries had been done, for examples in healthcare field [4], implementation BI in some industries in Norway [3] and BI implementation for SME [5] and BI implementation for mobile application [6].

The BI and analytics platform market's shift from IT-led reporting to modern business-led analytics. Data and analytics leaders face countless choices from traditional BI vendors that have closed feature gaps and innovated, to disrupters continuing to execute [7]. Some BI vendors are SAP, Oracle, Pentaho, Odoo, SAS, IBM, Microsoft, etc.

BI applications have capabilities: analysis, such as online analytical processing (OLAP), information delivery, such as dashboards and reports; and platform integration, such as a development environment and BI metadata management. BI application helps company to readily access and analyses the reliable company information timely to help company make insightful business decisions and meet their objectives.

However, implementing a BI application can be an expensive and how can company ensure that they will get the return on investment from BI application implementation. Some best practice guidance that will help company implement BI application that meet their needs and add value to the decision-making process [8]:

1. Identify business needs

The first step in implementing an effective BI solution is to identify as clearly as possible the business need that will be addressed.

2. Involve business users

Affected business users should be encouraged to identify the reports that they currently run together with the system that provides the data.

3. Select the right system

Identify which of the many solutions available will best meet the needs of the business and the end-users

4. Decide on migration method

A decision will need to be made about the best way to integrate data from existing databases and applications.

5. Incorporate familiar Environments

Business users prefer BI applications that provide them with a familiar environment in which to work.

2.2 Open Source ERP:

Open source ERP software has privilege in cost. Open source software is software that is freely available with source code. Anyone can edit, modify and distribute to anyone for any purpose and with a free license and no ownership permit [9]. Some types of open source ERP are Compiere, OpenBravo, ADempiere, Odoo, WebERP, Dolibarr ERP, Sugar CRM, etc. The software is a license-free web-based software using languages like Phyton, Javascript, Php, Frappe, etc. Each 
has various modules such as human resources, sales management, inventory, finance, etc. Customization process can also be done to adjust to company business process.

\subsection{Odoo ERP:}

Odoo (formerly known as Open ERP and before that, Tiny ERP) is an open source platform that is used for business purposes. Odoo has existed since February 2005 under the name Tiny ERP. Integrated modules are built on the platform, covering all business areas ranging from CRM, sales, accounting and stock [10]. Odoo is classified as Enterprise Resource Planning (ERP) software. This software was developed by Odoo S.A, which has more than 250 employees. Odoo's representatives are spread across Belgium, San Francisco, New York, Luxembourg, India and Hong Kong. Odoo is built open source and modular, so Odoo supports the reuse of existing libraries and everyone can be involved in the development. Odoo is released under the AGPL (Affero General Public License) license. More than 1500 developers joined in the Odoo community. There are over 4500 modules to address the business needs of more than $2,000,000$ users worldwide [11].

The Odoo platform consists of three main components, the PostgreSQL database, the Odoo server application, and the web server. The PostgreSQL database holds all data associated with the data and the Odoo configuration. The Odoo application server contains libraries and compiler modules built using the Python programming language. The web server handles client requests from the web browser. Odoo Architecture can be seen in Figure 1.

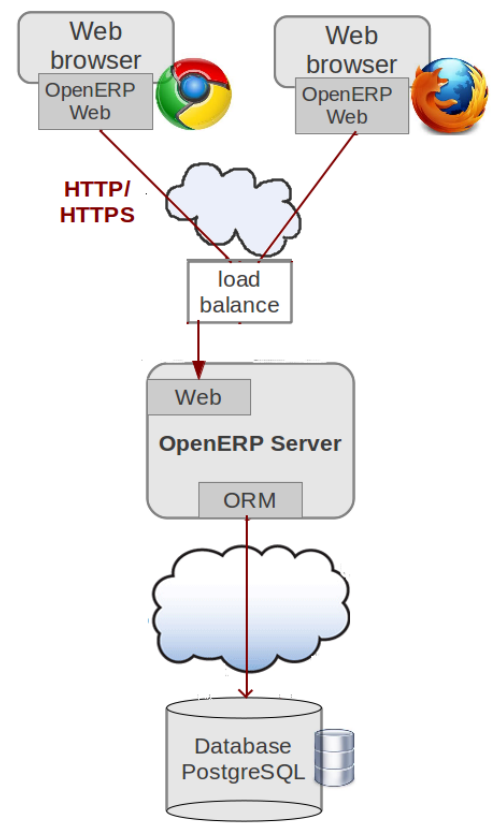

Fig. 1: Odoo Architecture [11]

Odoo is built using the Open Object framework [11]. Open Object is a framework that is modular, scalable, and supports Rapid Application Development (RAD). Odoo provides basic modules that support basic business functions within a company. Odoo has an open architecture. The developer team has the ability to design, develop and deploy a software system that exactly matches the intended companies' operations. Odoo is also web-based responsive and able to support all devices and operating systems.

2.4 Odoo Business Intelligence:

Odoo has limited features of BI. To extract very specific information out of the system developers are needed. External packages are often used (such as Pentaho or Jasper Reporting) to analyse and process Odoo data. The features of Odoo BI are [12]:

1. Tabular chart

Get an overview of all data in one single table that is fully adaptable to the field of research.

2. Bar, line and pie charts

Switch between different view styles for the same data to capture the most demonstrative view.

3. Filter data

Use built-in filters to gather information within the research field and create custom filters that we can save and use later.

4. Export data

Create Excel ${ }^{\circledR}$ spreadsheet documents from the collected data.

5. Customize board

Create custom board containing only information that we consider more relevant to business.

6. Save Favorites

Create filters and save them in a favorites list to instantly access them afterwards.

3 Case Study:

In this section, will be piloted a BI module in Odoo ERP. A case study was taken at a distributor company in Surabaya. Figure 2 is some of the sales order data that occurred in May 2017. These sales data are taken from Sales Modules in Odoo ERP [13]. 


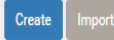

\section{Order Number}

- 2017/05/S0/AM/00077

口 2017/05/S0/AM/00074

口 2017/05/S0/AM/00073

[] 2017/05/S0/AM/00072

- 2017/05/S0/AM/00071

[- 2017/05/S0/Am/0008

- 2017/05/S0/AM/00068

- 2017/05/S0/Am/0006

- 2017/05/S0/AM/00066

— 2017/05/S0/AU/00235

- 2017/05/S0/AU/00233

- 2017/05/S0/AU/00232

[ 2017/05/SO/AU/00231

2017/05/SO/AU/00230

2017/05/S0/AU/00229

2017/05/S0/AU/00228

2017/05/S0/AU/0022

- 2017/05/S0/AU/00225

2017/05/S0/AU/00224

Fig. 2: Sales Data

\begin{tabular}{|c|c|}
\hline Order Date & Customer \\
\hline 05/12/2017 10:27:41 & INTEGRA INDO CABINET, PT \\
\hline 05/09/2017 08:57:00 & INTEGRA INDO CABINET, PT \\
\hline 05/09/2017 08:53:59 & Bp. MANSYUR \\
\hline 05/06/2017 09:29:26 & RUKUN JAYA TEKNIK 1 \\
\hline 05/06/2017 09:26:37 & WONOJATI WIJAYA, PT \\
\hline 05/06/2017 09:21:59 & LINGGARJATI MAHARDIKA MULLA, PT \\
\hline 05/05/2017 15:40:57 & BINA SATRIA ABADI SENTOSA, PT \\
\hline 05/05/2017 13:03:25 & PT. FELTICO UTAMA ABADI \\
\hline 05/04/2017 15:43:11 & INTEGRA INDO CABINET, PT \\
\hline 05/04/2017 15:25:48 & JAYA PRATAMA TEKNIK \\
\hline 05/04/2017 15:20:54 & CAHAYA INDO TEKNIK \\
\hline 05/04/2017 15:14:42 & CAHAYA INDO TEKNIK \\
\hline 05/04/2017 11:31:23 & UD. Mega Teknik-Malang \\
\hline 05/04/2017 10:32:37 & Kawan Lama - Bj.Negoro \\
\hline 05/04/2017 10:31:56 & CV.SUBUR REJEKI ABADI JAYA \\
\hline 05/04/2017 10:31:26 & Indo Motor - Sumenep \\
\hline 05/04/2017 10:29:23 & LANCAR ABADI \\
\hline 05/04/2017 10:28:37 & ANUGRAH JAYA TEKNIK \\
\hline 05/04/2017 10:27:28 & CAHAYA INDO TEKNIK \\
\hline
\end{tabular}

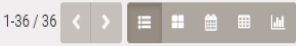

\begin{tabular}{|c|c|c|}
\hline Salesperson & Total & Invoice Status \\
\hline Ainul & Rp $505,400,000.00$ & Fully Invoiced \\
\hline Ainul & Rp $246,050,000.00$ & Fully Invoiced \\
\hline Ainul & $\operatorname{Rp} 33,150,000.00$ & Fully Invoiced \\
\hline Ainul & $\$ 1,945.00$ & Fully Invoiced \\
\hline Ainul & $\$ 2,450.00$ & Fully Invoiced \\
\hline Ainul & $\$ 244,000.00$ & To Invoice \\
\hline Ainul & $\$ 5,600.00$ & Fully Invoiced \\
\hline Ainul & $\$ 6,325.00$ & Fully Invoiced \\
\hline Ainul & $\$ 6,100.00$ & Fully Invoiced \\
\hline Rita & Rp $25,270,000.00$ & To Invoice \\
\hline Rita & $\operatorname{Rp} 6,750,000.00$ & Fully Invoiced \\
\hline Rita & $\operatorname{Rp} 49,640,000.00$ & To Invoice \\
\hline Rita & Rp 8,200,000.00 & Fully Invoiced \\
\hline Rita & Rp $3,600,000.00$ & Fully Invoiced \\
\hline Rita & Rp 20,250,000.00 & Fully Invoiced \\
\hline Rita & Rp $7,300,000.00$ & Fully Invoiced \\
\hline Rita & $\operatorname{Rp} 5,000,000.00$ & Fully Invoiced \\
\hline Rita & Rp $5,000,000.00$ & Fully Invoiced \\
\hline Rita & $\operatorname{Rp} 11,375,000.00$ & Fully Invoiced \\
\hline
\end{tabular}

For sales report, it can be seen based on some measure, e.g. for sales data per supplier, size can be based on total invoiced, quantity invoiced, quantity delivered etc. It can be viewed in the form of pivot table or graph as in Figure 3.

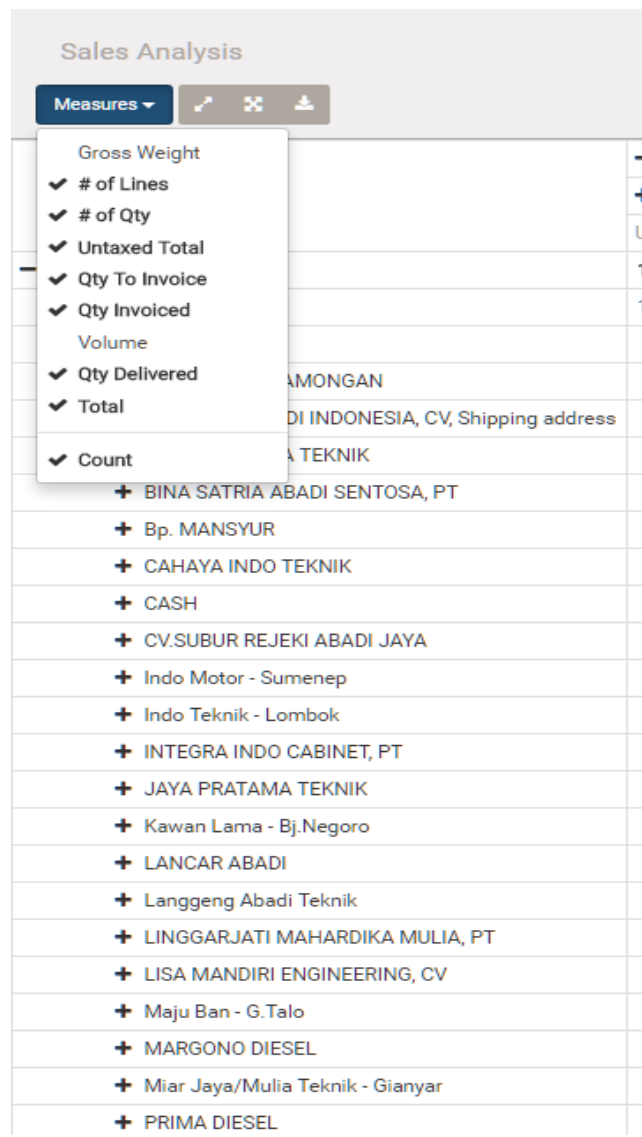

\begin{tabular}{|c|c|c|c|c|c|c|c|}
\hline - Total & & & & & & & \\
\hline + Direct Sales & & & & & & & \\
\hline Untaxed Total & \# of Qty & \# of Lines & Qty To Invoice & Qty Invoiced & Qty Delivered & Total & Count \\
\hline $1,152,256,658.14$ & 262.00 & 70 & 76.00 & 186.00 & 191.00 & $1,227,493,023.96$ & 70 \\
\hline $1,152,256,658.14$ & 262.00 & 70 & 76.00 & 186.00 & 191.00 & $1,227,493,023.96$ & 70 \\
\hline $5,850,000.00$ & 1.00 & 1 & 0.00 & 1.00 & 1.00 & $5,850,000.00$ & 1 \\
\hline $22,000,000.00$ & 10.00 & 2 & 0.00 & 10.00 & 10.00 & $22,000,000.00$ & 2 \\
\hline 1.14 & 2.00 & 2 & 0.00 & 2.00 & 2.00 & 1.26 & 2 \\
\hline $5,000,000.00$ & 2.00 & 1 & 0.00 & 2.00 & 2.00 & $5,000,000.00$ & 1 \\
\hline 0.42 & 1.00 & 1 & 0.00 & 1.00 & 1.00 & 0.47 & 1 \\
\hline $30,136,363.64$ & 1.00 & 1 & 0.00 & 1.00 & 1.00 & $33,150,000.00$ & 1 \\
\hline $67,765,000.00$ & 33.00 & 13 & 12.00 & 21.00 & 21.00 & $67,765,000.00$ & 13 \\
\hline $800,000.00$ & 1.00 & 1 & 0.00 & 1.00 & 1.00 & $800,000.00$ & 1 \\
\hline $20,250,000.00$ & 25.00 & 1 & 0.00 & 25.00 & 25.00 & $20,250,000.00$ & 1 \\
\hline $7,300,000.00$ & 10.00 & 1 & 0.00 & 10.00 & 10.00 & $7,300,000.00$ & 1 \\
\hline $10,350,000.00$ & 10.00 & 2 & 0.00 & 10.00 & 10.00 & $10,350,000.00$ & 2 \\
\hline $683,136,364.09$ & 6.00 & 4 & 0.00 & 6.00 & 6.00 & $751,450,000.51$ & 4 \\
\hline $25,270,000.00$ & 6.00 & 5 & 4.00 & 2.00 & 2.00 & $25,270,000.00$ & 5 \\
\hline $13,455,000.00$ & 10.00 & 4 & 7.00 & 3.00 & 3.00 & $13,455,000.00$ & 4 \\
\hline $5,000,000.00$ & 1.00 & 1 & 0.00 & 1.00 & 1.00 & $5,000,000.00$ & 1 \\
\hline $19,208,000.00$ & 2.00 & 1 & 0.00 & 2.00 & 2.00 & $19,208,000.00$ & 1 \\
\hline 18.48 & 9.00 & 8 & 3.00 & 6.00 & 6.00 & 20.33 & 8 \\
\hline $39,090,909.09$ & 1.00 & 1 & 0.00 & 1.00 & 1.00 & $43,000,000.00$ & 1 \\
\hline $22,800,000.00$ & 3.00 & 1 & 0.00 & 3.00 & 3.00 & $22,800,000.00$ & 1 \\
\hline $2,300,000.00$ & 5.00 & 1 & 0.00 & 5.00 & 5.00 & $2,300,000.00$ & 1 \\
\hline $55,040,000.00$ & 8.00 & 4 & 1.00 & 7.00 & 0.00 & $55,040,000.00$ & 4 \\
\hline $15,000,000.00$ & 25.00 & 1 & 0.00 & 25.00 & 25.00 & $15,000,000.00$ & 1 \\
\hline
\end{tabular}

Fig. 3: Sales Analysis in Pivot Table View 
We can do data filtering process group by any fields (Fig 4), such as group by customer and product in pivot table or graph view, as in Figure 5, 6 and 7. The report includes the total sales per customer per product, total orders per customer(Fig 6), total sales per product (Fig 7)

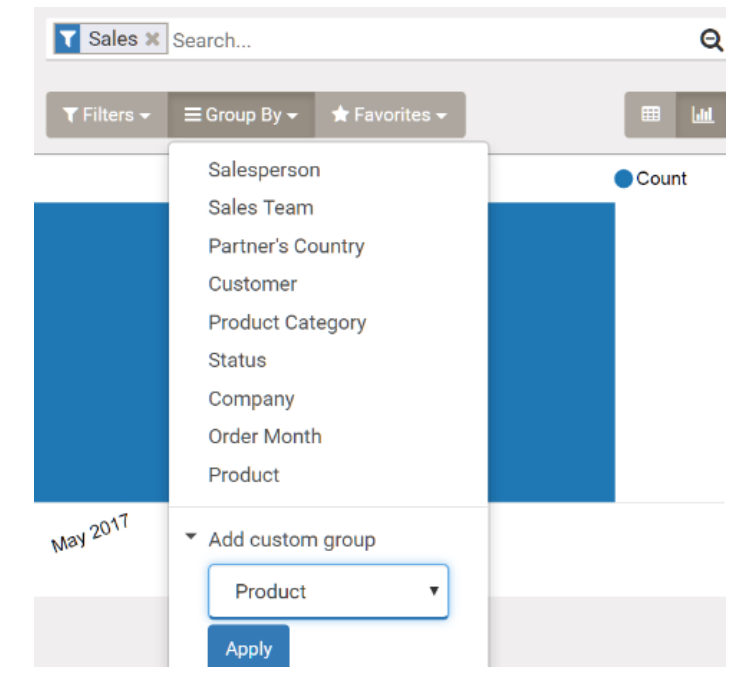

Fig. 4: Filtering Process

\begin{tabular}{|c|c|c|c|c|c|c|c|c|}
\hline & \multicolumn{8}{|l|}{ - Total } \\
\hline & \multicolumn{8}{|l|}{ + Direct Sales } \\
\hline & Untaxed Total & \# of Qty & \# of Lines & Qty To Invoice & Qty Invoiced & Qty Delivered & Total & Count \\
\hline - Total & $3,972,012,608.01$ & $1,916.00$ & 302 & 76.00 & 186.00 & 191.00 & $4,146,058,798.81$ & 302 \\
\hline - AAN JAYA DIESEL & $26,975,000.00$ & 75.00 & 3 & 0.00 & 0.00 & 0.00 & $26,975,000.00$ & 3 \\
\hline$+[$ [JDM-FFC23] Disk Mill FFC-23 & $23,500,000.00$ & 20.00 & 1 & 0.00 & 0.00 & 0.00 & $23,500,000.00$ & 1 \\
\hline + [JMSH-SH90CM] Straight Head Sprayer 90 CM SH-90 & $1,300,000.00$ & 50.00 & 1 & 0.00 & 0.00 & 0.00 & $1,300,000.00$ & 1 \\
\hline + [SDAH-3PLYX100] SPRAY HOSE 3PLY SHODA 8.5MMx14,5MMx100M & $2,175,000.00$ & 5.00 & 1 & 0.00 & 0.00 & 0.00 & $2,175,000.00$ & 1 \\
\hline
\end{tabular}

Fig. 5: Report per Customer and Product - Pivot View

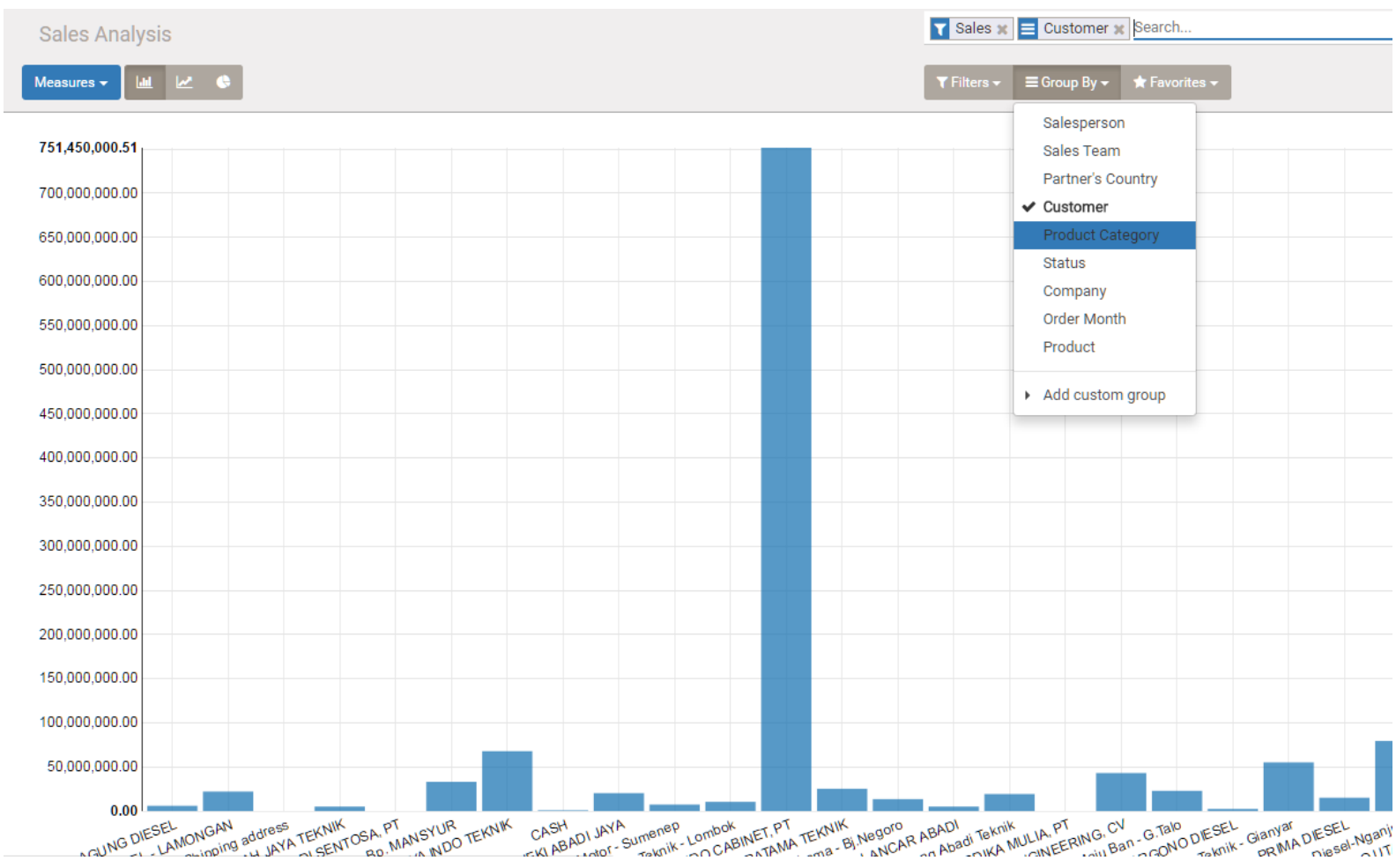

Fig. 6: Report per Customer - Graph View 
Citation: Yulia Kendengis and Leo Willyanto Santoso, 2018. Integration Between ERP Software and Business Intelligence in Odoo ERP: Case Study A Distribution Company. Advances in Natural and Applied Sciences., 12(4): 16-21.

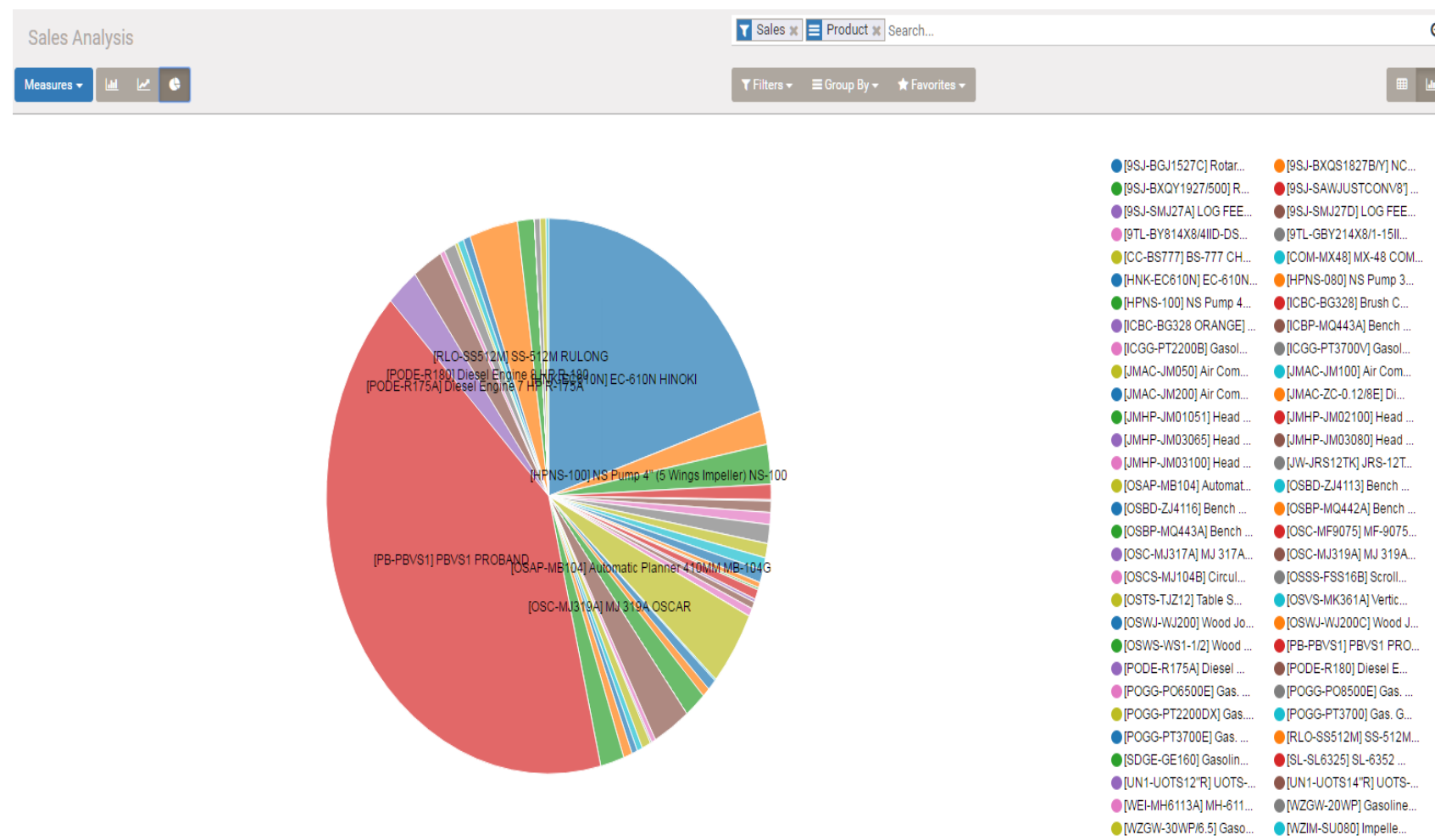

Fig. 7: Report per Product - Graph View

For each filtering that has been done can be stored in favorites and / or inserted into the dashboard of the Sales module.

Figure 8 is a dashboard example for the Accounting module. We can quickly find out some information such as where the bills of both debt and receivables are due, how the current cash position etc. on this dashboard.

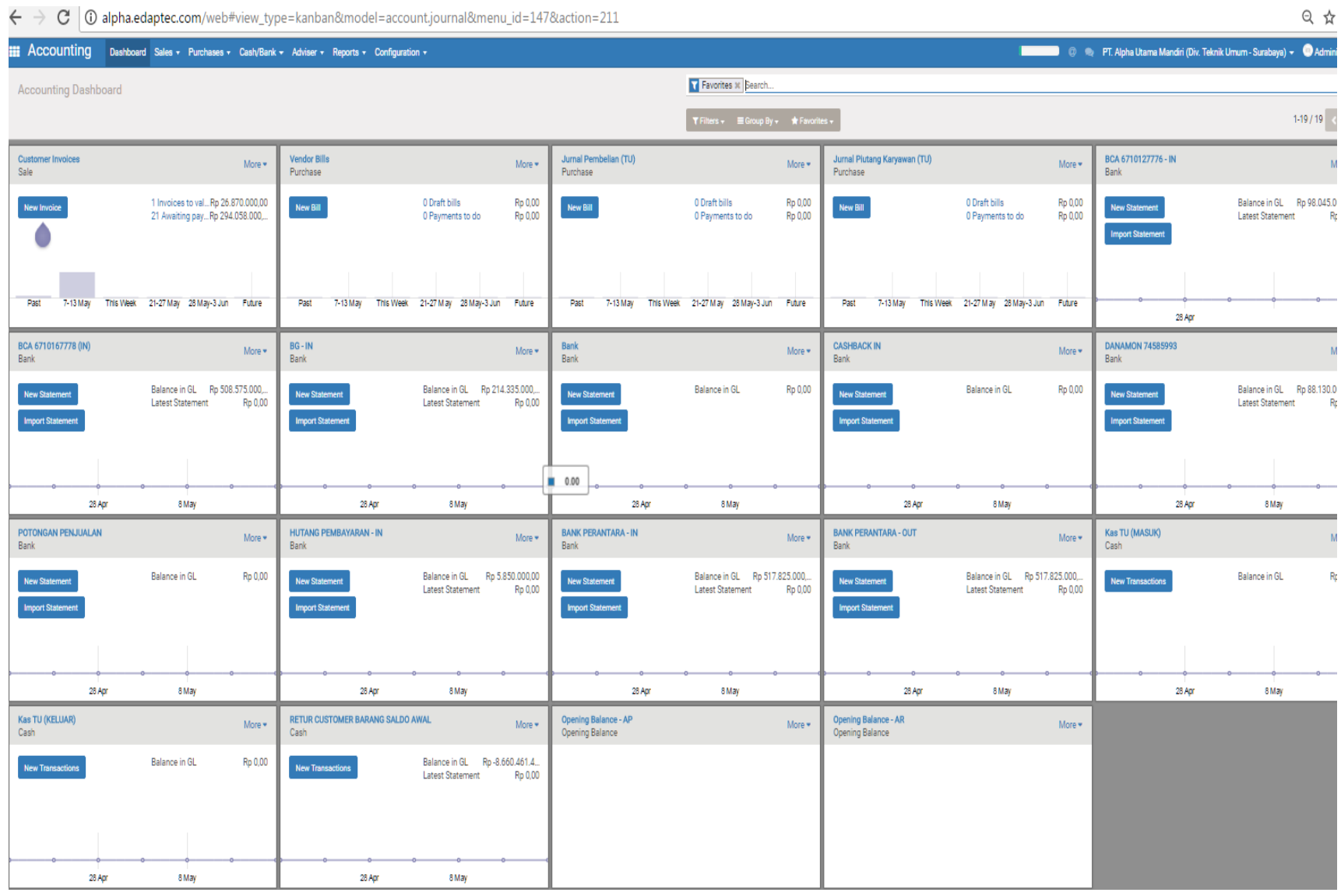

Fig. 8: Accounting Dashboard

Figure 9 is an inventory dashboard, where we can find out what items will be in and out both from outside the company and between warehouses within the company. 


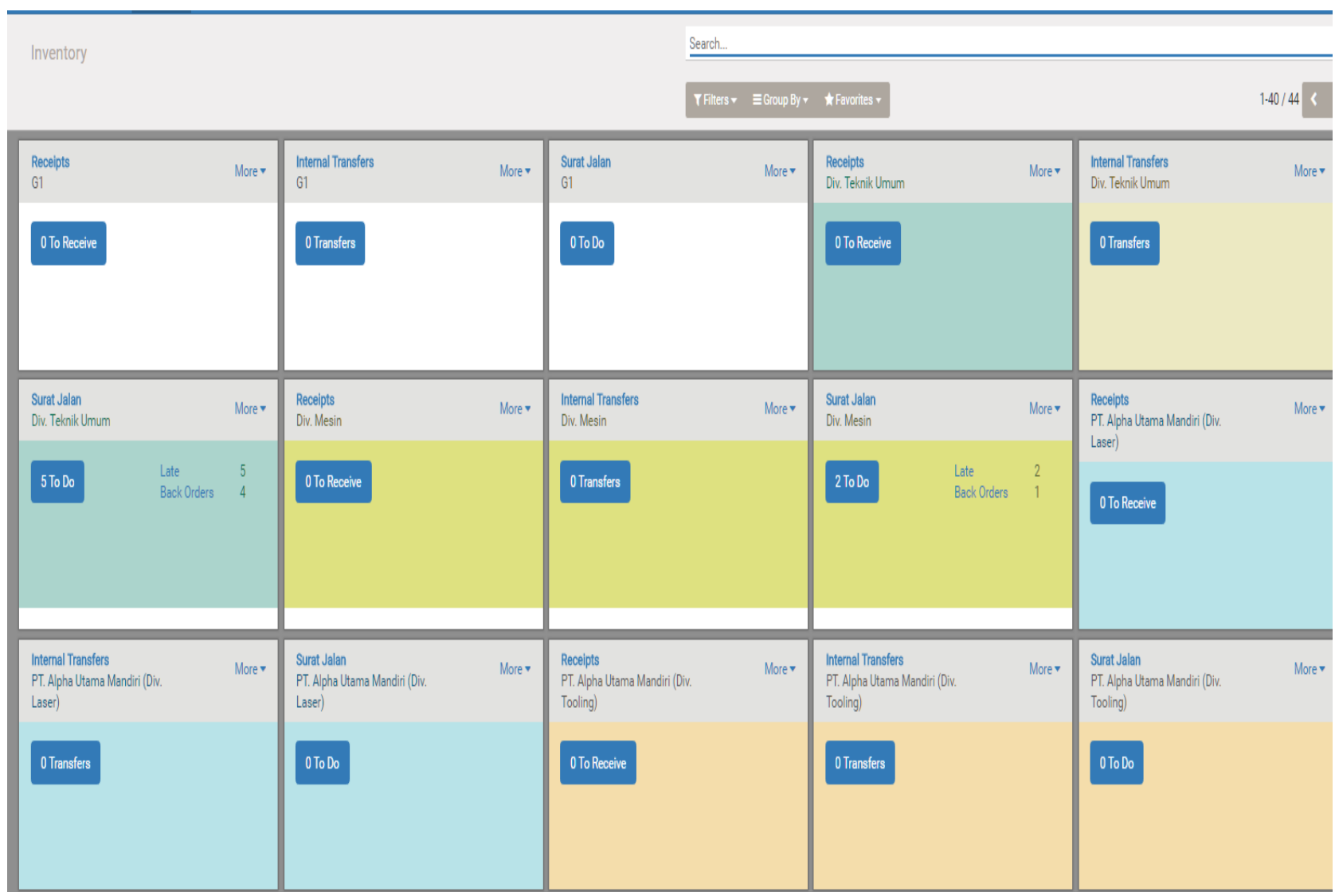

Fig. 9: Inventory Dashboard

We can also create specific reports and analysis on the go in a few simple clicks, based on existing templates or on personalized criteria.

Conclusion:

The integration between BI and ERP module in Odoo ERP has helped to provide information for the company and assist in decision making. Company can also create specific reports and analysis on the go in a few simple clicks, based on existing templates or on personalized criteria. As an open sorce ERP Software, Odoo ERP give many benefits for the company: lower cost of implementation, providing information to the company that can improve efficiency and effectiveness of decisions, powerful tools for data analysis and visualization, and provides a web-based accessibility so it can be accessed anytime and anywhere.

\section{REFERENCES}

[1] Watson, H., 2009. Tutorial: Business Intelligence - Past, Present, and Future, Communications of the AIS.

[2] Turban, E., R. Sharda and D. Delen, 2014. Decision Support and Business Intelligence Systems, Pearson New International Edition.

[3] Presthus, W. and S. Sæthre, 2015. The Secret of my Success: An exploratory study of Business, Procedia Computer Science., 64: 240-247.

[4] Pereiraa, A., F. Portela, M.F. Santosa, J. Machadoa and A. Abelhaa, 2016. "Pervasive Business Intelligence: A new trend in Critical Healthcare," in The 6th International Conference on Current and Future Trends of Information and Communication Technologies in Healthcare (ICTH 2016), Procedia Computer Science., 98: 362-367.

[5] Tutunea, M.F. and R.V. Rus, 2012. "Business Intelligence Solution for SME's," in Emerging Market Queries in Finance and Business , Procedia Economics and Finance, 3: 865-870.

[6] Tutunea, M.F., 2015. "Business Intelligence Solutions for Mobile Devices - an Overview," in 22nd International Economic Conference - IECS 2015 "Economic Prospects in the Context of Growing Global and Regional Interdependencies", IECS 2015, Procedia Economics and Finance, 27: 160-169.

[7] Sallam, R.L., C. Howson, C.J. Idoine, T.W. Oestreich, J.L. Richardson and J. Tapadinhas, 2017. "Magic Quadrant for Business Intelligence and Analytics Platforms," 1602 2017. [Online].

[8] Data Meaning Services Group Inc, 2016. "Business Intelligence Best Practices: How to Support Insightful Decision Making," [Online].

[9] Dinesh, E. and T. Vetrivel, 2015. "Study on Open ERP for Start-Up SMEs," Paripex Indian Journal of Research, pp: 355-356.

[10] Moss, G., 2013. Working with OpenERP, Birmingham: Packt Publishing Ltd.

[11] O.S.A, 2015. "About Us-Odoo," [Online]. Available: https://www.odoo.com/page/about-us.

[12] Odoo, 2017. "https://www.odoo.com/page/business-intelligence-features," 2017. [Online].

[13] Reis, D., 2015.Odoo Development Essentials, Birmingham: ackt Publishing Ltd. 